Int. J. Dev. Biol. 51: 161-165 (2007)

doi: $10.1387 / \mathrm{ijdb} .062185 \mathrm{jh}$

Developmental Expression Pattern

\title{
Expression of Bmp ligands and receptors in the developing Xenopus retina
}

\author{
JENNIFER C. HOCKING and SARAH McFARLANE* \\ University of Calgary, Hotchkiss Brain Institute, Calgary, Canada.
}

\begin{abstract}
Bone morphogenetic proteins (BMPs) act repeatedly in the development of nervous system tissues. While BMP signaling is critical for the early growth and patterning of the eye, we are interested in possible later functions of BMPs in the morphological development of retinal neurons and formation of synaptic connections. Therefore, we conducted an in situ hybridization analysis of the mRNA expression for the ligands Bmp2, -4 and 7 and the type la, lb and II receptors (Bmprla, Bmprlb and Bmprll) during development of the retina of Xenopus laevis. Bmp4 mRNA is expressed in the dorsal retina and $B m p 7$ in the distal peripheral retina during the period of cell differentiation, while $B m p 2$ is not present in the eye. The type I receptors are expressed predominantly ventrally, from the optic vesicle stage until at least stage 35/36, after most cells have differentiated and many synaptic connections have formed. Bmprll mRNA, however, is distributed evenly across the dorsoventral axis, with highest expression in retinal ganglion cell and inner nuclear layers.
\end{abstract}

KEY WORDS: ALK3, ALK6, BMP, Xenopus, retinal development

The retina responds to light, processes visual information and transmits an image of the outside world to brain centers. For such complex functioning, the cells of the retina must be specified, arranged and connected to one another and to the brain in a carefully organized manner. Extrinsic molecules help to accomplish this by establishing the seven neural cell types of the retina, setting up the laminar structure, specifying dorsal-ventral and nasal-temporal differences and establishing topographic connections between the output neurons of the eye, retinal ganglion cells (RGCs) and the visual centers of the brain.

Bone morphogenetic proteins (BMPs), members of the transforming growth factor $\beta$ (TGF $\beta$ ) family of signaling molecules, are critical for nervous system development (Mehler et al., 1997). The approximately 20 BMP ligands are secreted and signal through binding to complexes of type I and II serine/threonine kinase receptors. There is a single BMP type II receptor (BMPRII) and two type I receptors (BMPRIa/ALK3 and BMPRIb/ALK6), all of which are specific for BMP ligands. In some cases, BMPs also signal through activin type I (ALK2/ActRla) and type II (ActRII and ActRIIB) receptors (Chen et al., 2004). Upon ligand binding, the type II BMP or activin receptor phosphorylates a type I receptor near its cytoplasmic kinase domain, activating downstream signaling through phosphorylation of intracellular Smad proteins, which translocate to the nucleus and effect changes in transcriptional activity (Shi and Massague, 2003).
In the eye, specific BMPs are important for multiple aspects of early retinal and lens development, as revealed mainly by the analysis of mice mutant for BMPs or their receptors. In Bmp7null embryos, the eye cup stops growing and degenerates, resulting in micropthalmia or anopthalmia (Dudley et al., 1995). BMP4 patterns gene expression and cell identities within the dorsal retina and induces ectoderm overlying the mouse optic cup to form lens tissue (Furuta and Hogan, 1998;Sasagawa etal., 2002). The Bmprla/Bmprlb double knockouts have severe eye defects including reduced growth and failure of retinal neurogenesis, while mice with only one copy of Bmprlb in a Bmprla null background exhibit dorsoventral patterning defects without changes in growth or layering (Murali et al., 2005).

BMPs are obviously crucial in early eye patterning and growth; however, these early roles have prevented the analysis of the importance of BMP signaling in later events such as cell differentiation and morphological development. Xenopus laevis is a particularly useful model for studying development at a single cell level. By using methods that generate mosaic expression of DNA constructs late when cells are differentiating, the importance of

Abbreviations used in this paper: BMP, bone morphogenetic protein; BrdU, Bromodeoxyuridine; CMZ, ciliary marginal zone; INL, inner nuclear layer; ONL, outer nuclear layer; RGC, retinal ganglion cell; RGCL, retinal ganglion cell layer; TGF $\beta$, transforming growth factor $\beta$.

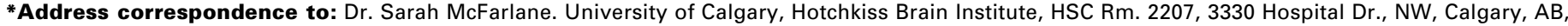
Canada T2N 4N1. Fax: +1-403-270-0737. e-mail: smcfarla@ucalgary.ca
} 

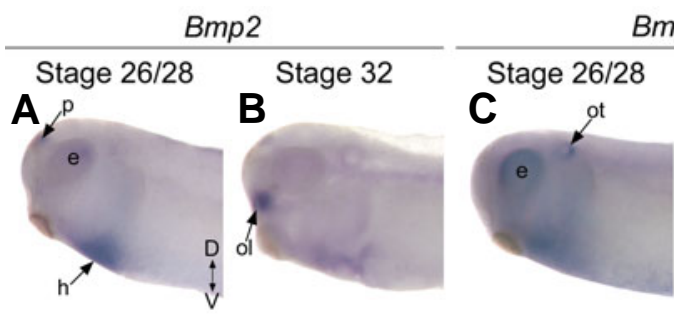

Bmp4
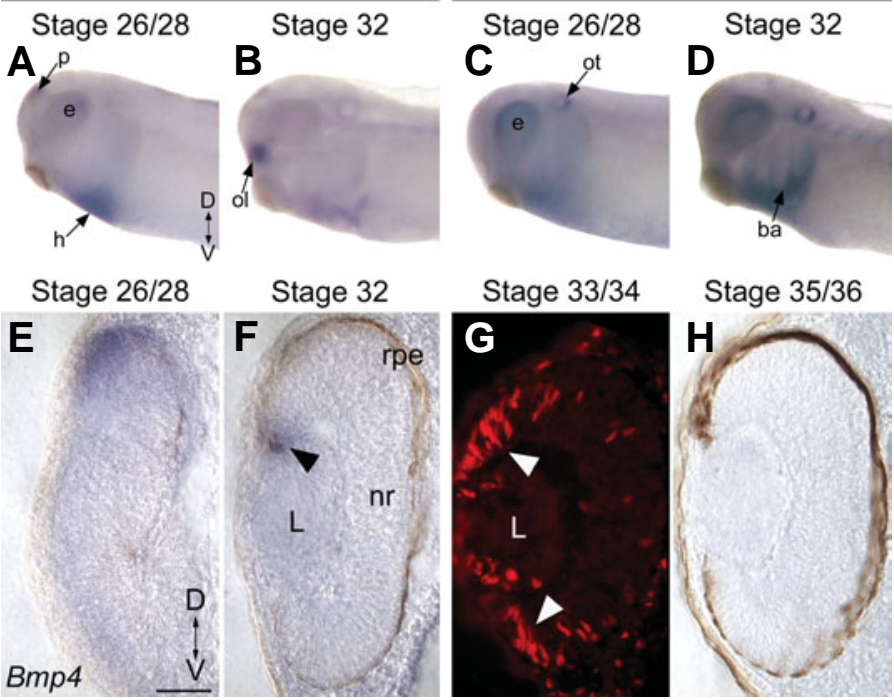

Fig. 1. Bmp4 mRNA, but not Bmp2, is expressed in the forming Xenopus retina. (A,B) Spatial expression of Bmp2 mRNA in Xenopus embryos processed for wholemount in situ hybridization using digoxigenin-labeled riboprobe. Lateral views of stage 26/28 (A) and stage 32 (B) embryos. (C,D) Expression of Bmp4 mRNA in wholemount embryos at stages 26/28 (C) and 32 (D). (E,F,H) Transverse sections through retinas of embryos processed for Bmp4 in situ hybridization at stages 26/28 (E), 32 (F) and 35/36 (H). (G) Immunolabeling of BrdU that has incorporated into dividing cells at stage 33/34 shows the location of the ciliary marginal zone (CMZ; white arrowheads), a proliferative region adjacent to the lens. Compare with Bmp4 expression (black arrowhead) at stage 32 (F). Anterior is to the left in panels (A-D). Scale bar in (E) is $50 \mu \mathrm{m}$ for $(E-H)$. Abbreviations: $D$, dorsal; $V$, ventral; ba, branchial arches; $e$, eye; $h$, heart; $L$, lens; $n r$, neural retina; $p$, pineal gland; ol, olfactory pits; ot, otic vesicle; rpe, retinal pigmented epithelium.

signaling pathways in the morphological development of individual cells can be assessed (Riehl et al., 1996). We have conducted a detailed analysis of Bmpligand and receptor mRNA expression during development of the retina of Xenopus laevis. This study will help in the further elucidation of the complex functions of BMPs during retinal development.

\section{Results and Discussion}

\section{Bmp4 and -7 mRNA are expressed in the developing Xeno- pus retina}

We examined the expression of Bmp2, Bmp4 and Bmp7 mRNA from early proliferative to later differentiating stages of retinal development. The first cells to be born in the developing eye primordium at stage 24 are the RGCs (Holt et al., 1988). Shortly after, cones and amacrine cells are born, followed by rod and bipolar cells and finally by Müller glia. At stages $26 / 28$, most cells in the retina are proliferating and the eye is still an optic vesicle. By stage 32 , the eye cup has formed and while some cells continue to divide, the RGC layer (RGCL) is present and most RGC axons have exited the eye. By stage 35/36, the retina is fully laminated, all the different cell types are represented and many synaptic connections have formed.

At stages 26/28, Bmp2is expressed in the pineal gland and the presumptive heart (Fig. 1A). This expression continues through stage 32, when the olfactory pits initiate expression (Fig. 1B). Bmp2mRNA was never detected within the eye at tailbud stages. In contrast, $B m p 4 \mathrm{mRNA}$ is strongly expressed in the dorsal retina at stage $26 / 28$, as well as by the otic vesicle and presumptive heart (Fig. 1C). By stage 32, Bmp4mRNA is reduced in the retina, but has expanded into the branchial arches (Fig. 1D). Transverse sections demonstrate that $B m p 4 \mathrm{mRNA}$ is strongly expressed in the distal portion of the dorsal optic vesicle at stage $26 / 28$, but becomes restricted after optic cup formation to the dorsal ciliary marginal zone (CMZ), a proliferative region adjacent to the lens (stage 32; Fig. 1E,F). Incorporation of bromodeoxyuridine (BrdU) by dividing cells at stage $33 / 34$ highlights the CMZ (white arrowheads, Fig. 1G). By stage 35/36, Bmp4 mRNA expression is lost (Fig. 1H).

$B m p 7 \mathrm{mRNA}$ is robustly expressed within the periphery of the retina at stage $26 / 28$, while being excluded from the central retina. The ventral-most region lacks $B m p 7$ expression, likely because the retina later closes over the optic nerve at this region (Fig. 2A). Retinal expression is reduced to a ring surrounding the lens by stage 32 (Fig. 2B). The heart and otic vesicle express Bmp7 mRNA at stages 26/28 and 32, while branchial arch expression begins by stage 32 . In sections through both the central and peripheral retina, $B m p 7 \mathrm{mRNA}$ is expressed strongly in the distal portion of the optic vesicle (Fig. 2C,D). With the formation of the

Fig.2. Expression of Bmp7 mRNA in the Xenopus retina during development. (A,B) Xenopus embryos processed for wholemount in situ hybridization with $\mathrm{Bmp} 7$ antisense riboprobe at stages 26/28 (A) and 32 (B). (C) Transverse section through the central portion of the optic vesicle of a stage 26/28 embryo labeled for Bmp7 mRNA (see line 1 in A). (D) Transverse section through the peripheral retina of stage 26/28 embryo lline 2 in A) reveals expression of Bmp7 mRNA along the entire dorsoventral axis. (E) Transverse section through a stage 32 embryo shows Bmp7 expression in the dorsal and ventral CMZ (black arrowheads). (F) A patch of Bmp7 expression (arrow) appears in the mesenchyme ventral to the retina at stage 35/36. Anterior is to the left in panels $(A, B)$. Scale bar in (C) for panels (C-F) is $50 \mu \mathrm{m} .{ }^{*}$ in $(C, D)$ shows the location of the interior of the optic vesicle prior to invagination of the optic cup. D, dorsal; $V$, ventral; ba, branchial arches; $h$, heart; $L$, lens; $n r$, neural retina; ot, otic vesicle; rpe, retinal pigment epithelium.
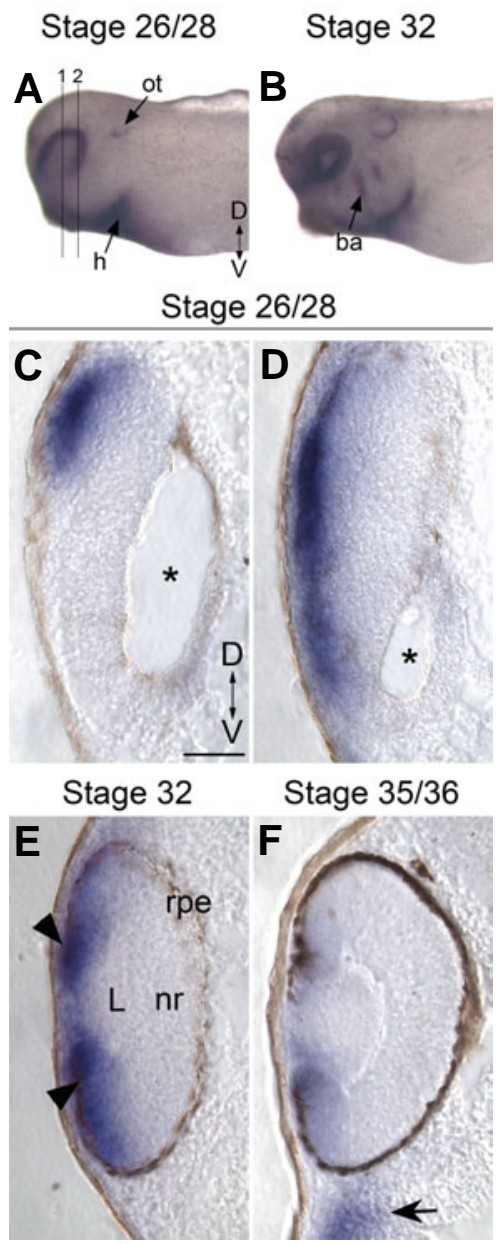
eye cup by stage 32, Bmp7expression has shifted to the dorsal and ventral CMZ (Fig. 2E, compare with $1 \mathrm{G}$ ). At stage $35 / 36$, the expression has weakened and remains mostly in the ventral $\mathrm{CMZ}$ (Fig. 2F).

BMP expression patterns show high conservation, but also some notable variations across species. For instance, while Bmp2 mRNA is expressed in the retinal pigmented epithelium (RPE) in mouse and is found in the RGCL and dorsal inner nuclear layer (INL) of the chick retina, the Xenopus retina does not express $\mathrm{Bmp2}$ at the stages examined here (Dudley and Robertson, 1997;Belecky-Adams and Adler, 2001). In Xenopus, as in other species, Bmp4 is generally found in the distal optic vesicle and dorsal optic cup during early retinal development (Dudley and Robertson, 1997;Belecky-Adams and Adler, 2001). Liu et al. (2003) also found expression in the RGCL at embryonic day 15 in mouse. In contrast to the restriction of $B m p 7$ expression to proliferative regions of the Xenopus retina, chick $B m p 7$ mRNA is made by RGCs throughout the period of cell differentiation and is strongly expressed in the dorsal outer nuclear layer (ONL) and INL during early retinal development (BeleckyAdams and Adler, 2001).

The apparent restriction of Xenopus Bmp4and 7 to dividing retina suggests roles in proliferation, cell fate specification or early differentiation events. However, the presence of these ligands in the marginal zone of the retina as the first RGC axons exit the eye hints at a different function. It is possible that BMPs repel RGC axons away from the $\mathrm{CMZ}$ and into the optic nerve head (Oster et al., 2004), similar to their actions on commissural neurons in the spinal cord (Butler and Dodd, 2003).

\section{Type I Bmp receptors are expressed predomi- nantly in the ventral retina}

We next examined the expression of the different BMP receptors in the developing retina. Bmprla mRNA expression is widespread in the embryo and can be detected in the kidney, otic vesicle, branchial arches, regions of the brain and in the eye (Fig. 3A). There is also a repeated chevronshaped pattern of expression along the trunk, likely in the intersomitic region. Transverse sections show that the eye expression is spread throughout the proliferating retina at stages 28 and 30 , with highest levels in the ventral region and lens and weaker expression in the presumptive RGCL adjacent to the lens (Fig. 3B,C). By stage 33/34, the central differentiated retina no longer expresses Bmprla, while the lens, ventral retina and dorsal CMZ are still strongly labeled (Fig. 3D). By stage 35/36, Bmprla mRNA remains only in the lens and the ventral CMZ (Fig. 3E).

$B$ mprlb mRNA expression is restricted to the head, where it is found in the branchial arches, otic vesicle, brain and eye (Fig. 3F). Within the retina, the Bmprlaexpression is generally limited to the
BmprIa
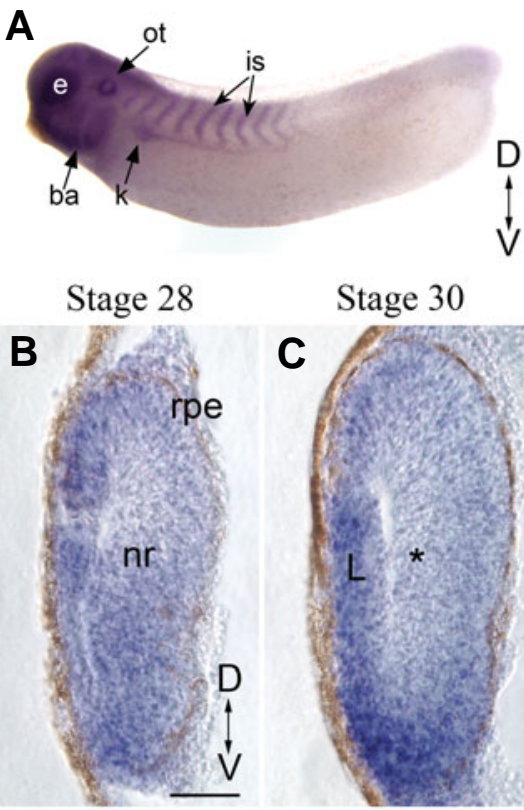

Stage $33 / 34$
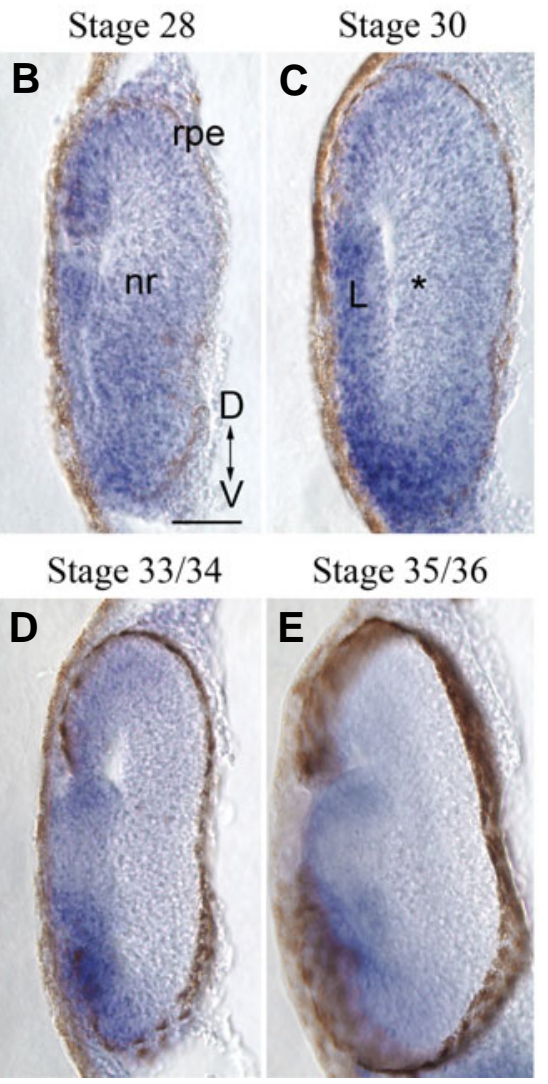

Stage $35 / 36$

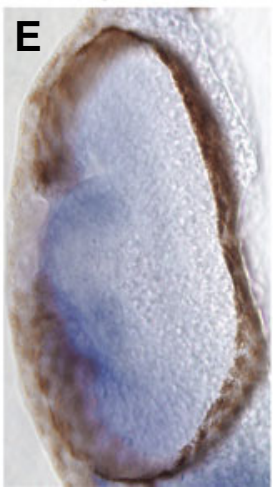

BmprIb
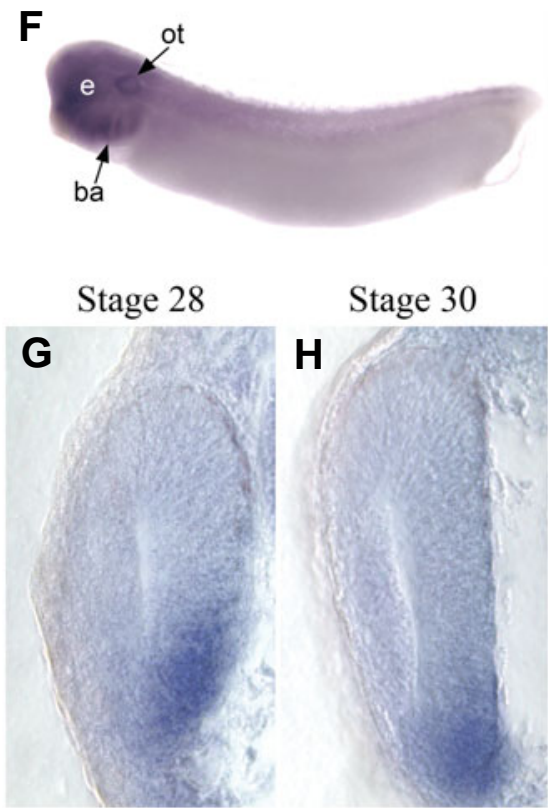

Stage $33 / 34$

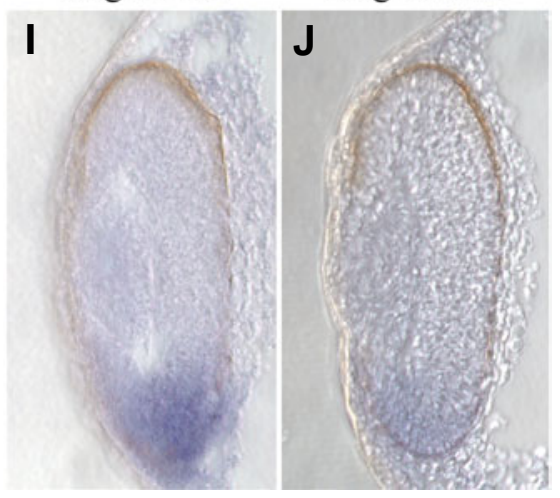

Fig. 3. Distribution of type I Bmp receptor transcripts in the developing Xenopus eye. (A) Wholemount in situ hybridization of a stage 28 embryo using a Bmprla antisense (B-E) Transverse sections through the retinas of Xenopus embryos processed for Bmprla in situ hybridization, at stages 28 (B), 30 (C), 33/34 (D) and 35/36 (E). * in (C) is the forming RGCL. (F) Bmpr1b wholemount in situ hybridization of a stage 30 embryo. (G-J) show expression of Bmprlb. Scale bar in (B) is $50 \mu \mathrm{m}$ for $(B-E)$ and (G-J). Abbreviations: $D$, dorsal; $V$, ventral; ba, branchial arches; e, eye; $k$, kidney; is, intersomitic region; $L$, lens; $n r$, neural retina; ot, otic vesicle; rpe, retinal pigment epithelium.

ventral retina and this becomes further refined as development progresses (Fig. 3G-J). Expression is weak at stage 35/36 and is lost by stage $37 / 38$ (Fig. 3J, data not shown).

The BmprlbmRNA pattern is highly conserved as expression in Xenopus, mouse and chick is strongest in the ventral retina (Belecky-Adams and Adler, 2001;Liu et al., 2003). In contrast, there are some species-specific differences in the retinal expression patterns of Bmprla. In mouse, Bmprla is expressed throughout the proliferating neural retina during optic cup formation, but decreases in postmitotic RGCs (Liu et al., 2003). This is similar to Xenopus, except that no dorsoventral differences are seen in mouse. In chick, Bmprla expression is higher ventrally in all cell 
layers at an early proliferative stage, as in Xenopus, but is then redistributed evenly across the retina after differentiation is complete and is expressed in a subset of cells in the INL and RGCL (Belecky-Adams and Adler, 2001).

Given the conservation of expression of $B m p r 1 b$, we can look to the Bmpr $1 b$ mutant mice to suggest the function of this receptor in Xenopus eye development. In Bmprlb null mice, many axons from the ventral retina make pathfinding errors before reaching the optic disc, likely due to the reduced expression of various axon guidance molecules in the retina (Liu et al., 2003).

\section{Bmprll mRNA is expressed in the inner layers of the retina}

Bmprl/mRNA, which codes for the only TGF $\beta$ type II receptor specific for BMPs (Chen et al., 2004), is expressed in the developing heart, otic vesicle, olfactory pits, brain and in the retina (Fig. 4A). Interestingly, Bmpr//mRNA is not expressed in a dorsoventral gradient in the retina, in contrast to the patterns of Bmpligands and type I receptors. At stage 28, mRNA for Bmprl/is expressed ubiquitously in the presumptive lens and proliferating neural retina (Fig. 4B). At stage 30, the expression resolves into a more layer-specific pattern with highest levels in the RGCL and INL and absence from the emerging photoreceptor layer or ONL (Fig. 4C). Expression is strongest around stage 33/34, weakening by stage $35 / 36$ and lost by stage $37 / 38$ (Fig. 4E, F, data not shown). Immunostaining of RGCs with an antibody against the transcription factor Islet-1 is shown for comparison to demonstrate that the Bmpr//mRNA expression includes, but is not limited to, the RGCL (Fig. 4D).

Bmprll expression in other species is consistent with the Xenopuspattern, with highest expression in the RGCL, some INL label and no dorsoventral gradient (Belecky-Adams and Adler, 2001; Liu et al., 2003). BMPRII is known to interact with the cytoplasmic kinase LIMK1, a regulator of actin dynamics, thereby linking BMP signaling to the cytoskeleton (Lee-Hoeflich et al., 2004). As such, the expression of Bmpr//in the RGCL and INL over the time that cells in these layers initiate and extend axons and dendrites argues for a role of BMPRII in the morphological differentiation of these cells.

With better knowledge of the retinal expression of Bmps and their receptors, the Xenopus system can now be used to assess late roles for BMPR signaling. Genetic constructs designed to either enhance or reduce BMPR signaling can be misexpressed within single retinal cells at late stages. Such an approach leaves intact the early patterning functions of BMPs and allows for development of mutant cells in a largely wildtype environment.

\section{Materials and Methods}

\section{Embryos}

Embryos were obtained by in vitro fertilization of eggs from $X$. laevis females who had been primed with human chorionic gonadotrophin (Intervet). Embryos were raised in 0.1X Modified Marc's Ringers (MMR; $0.1 \mathrm{M} \mathrm{NaCl}, 2 \mathrm{mM} \mathrm{KCl}, 1 \mathrm{mM} \mathrm{MgCl}, 5 \mathrm{mM}$ HEPES, $\mathrm{pH}$ 7.5) at 16-24을 and staged according to Nieuwkoop and Faber (1994).

\section{Wholemount in situ hybridization}

In situhybridization was performed as per Harland (1991). BM-Purple (Roche) was used as a chromogenic substrate. Xenopus Bmp2, Bmp4, Bmprla and Bmprl/cDNAs were kind gifts from Drs. S. Evans and A.H. Brivanlou. We obtained clones of the full-length Xenopus Bmp7(IMAGE
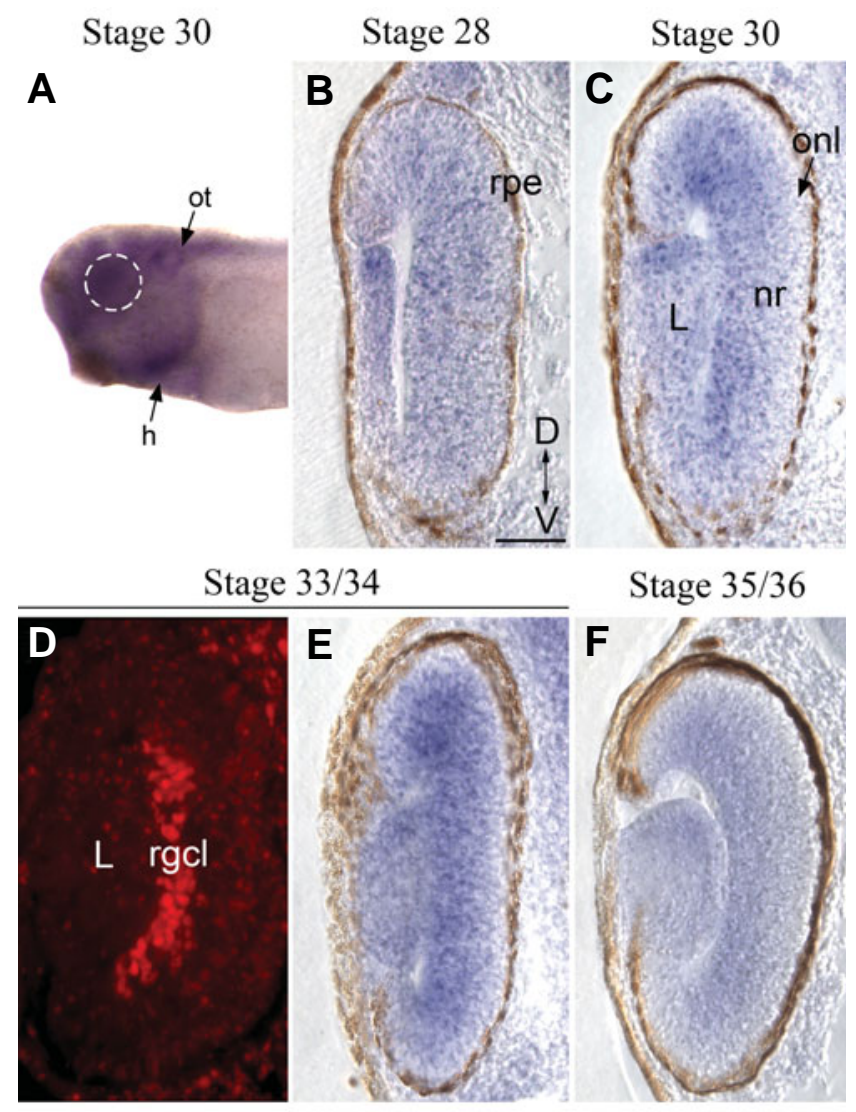

Stage $35 / 36$

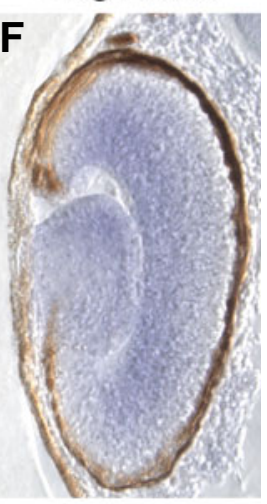

Fig. 4. Expression of Bmprll mRNA in the developing Xenopus eye. (A) Stage 30Xenopus embryo processed for Bmprll in situ hybridization. Bmprll transcripts are expressed in the eye (outlined by dotted line). (B,C, $\mathbf{E}, \mathbf{F})$ Ubiquitous expression of Bmprll mRNA in the stage 28 retina (B) becomes refined to the inner layers of the neural retina and the lens at stage 30 (C), 33/34 (E) and 35/36 (F). Expression is absent from the emerging photoreceptors in the outer nuclear layer (onl). (D) A retina immunolabeled for Islet-1 shows the location of the RGCs in the innermost layer of a stage 33/34 retina. Scale bar in (B) is $50 \mu \mathrm{m}$ for panels (BF). Abbreviations: $D$, dorsal; $V$, ventral; $h$, heart; $L$, lens; $n r$, neural retina; onl, outer nuclear layer; ot, otic vesicle; rgcl, retinal ganglion cell layer; rpe, retinal pigment epithelium.

4889064) and a Bmpr1bEST (IMAGE 3200976), from Open Biosystems. The Genbank accession numbers are X55031 (Bmp2), AJ005076 (Bmp4), BC055959 (Bmp T), D32066 (Bmprla), AW765822 (Bmprlb) and U81958 ( $B m p r /$ ). Results were consistent with every embryo processed for each probe and at least ten embryos per stage were examined.

\section{Vibratome sectioning}

For vibratome sectioning, embryos were mounted in gelatin/albumin blocks hardened with $25 \%$ glutaraldehyde. Sections were cut on a Series 1000 vibratome (Ted Pella, Redding, CA) at $50 \mu \mathrm{m}$, dried onto slides, dehydrated through a series of alcohol rinses, cleared in xylene and mounted under glass coverslips with Permount (Fisher Scientific Company). Wholemount and section pictures were taken on a Spot II camera using Spot Advanced Software (Diagnostic Instruments) and pictures were adjusted for brightness and contrast using Adobe Photoshop CS software.

\section{Immunohistochemistry}

To label dividing cells, stage 32 embryos were anesthetized in $1 \mathrm{X}$ 
Modified Barth's Saline [MBS; $8.8 \mathrm{mM} \mathrm{NaCl}, 0.1 \mathrm{mM} \mathrm{KCl}, 0.7 \mathrm{mM} \mathrm{CaCl}_{2}$, $0.1 \mathrm{mM} \mathrm{MgSO}_{4}, 5 \mathrm{mM}$ Hepes ( $\left.\mathrm{pH} 7.8\right), 25 \mathrm{mM} \mathrm{NaHCO}_{3}$ ] supplemented with $0.4 \mathrm{mg} / \mathrm{ml}$ tricaine (ethyl 3-aminobenzoic ethyl ester, methanesulfonate salt; Sigma-Aldrich Co.) and then injected in the belly with $5 \mathrm{mg} / \mathrm{ml}$ bromodeoxyuridine (BrdU; Sigma-Aldrich Co.) dissolved in MBS. Two hours after injection, embryos were fixed in $4 \%$ paraformaldehyde (PFA) in $1 \mathrm{X}$ phosphate buffered saline (PBS; $\mathrm{pH} 7.4$ ) overnight at $4^{\circ} \mathrm{C}$. Unmanipulated stage 33/34 embryos were also fixed in 4\% PFA to use for Islet-1 staining. Twelve $\mu \mathrm{m}$ transverse sections were cut on a cryostat, collected on gelatin-coated slides and processed for immunohistochemisty. Briefly, for Islet- 1 labeling, sections were incubated for 1.5 hours in Islet1 primary antibody (Developmental Studies Hybridoma Bank) diluted $1: 80$ in PBT [(1x PBS, $5 \%$ Triton-X (BDH), $0.2 \%$ bovine serum albumin (BSA; Sigma-Aldrich Co.)] with 5\% goat serum. For BrdU-injected embryos, an anti-BrdU labeling kit (Amersham) was used as instructed. Both primary antibodies were visualized with Rhodamine Red X (RRX; Jackson ImmunoResearch Laboratories, Inc.) goat anti-mouse secondary applied at 1:500 $(3 \mu \mathrm{g} / \mathrm{mL})$ for one hour. Slides were mounted with aquapolymount (Polysciences, Inc). Images were captured as described above for vibratome sections.

\section{Acknowledgments}

We would like to thank Xiolan Zhou and Peter Vize for excellent technical advice and Sarah Childs, Karen Atkinson-Leadbeater and Christine Webber for their helpful comments on the manuscript. S.M is a Canada Research Chair and an Alberta Heritage Foundation for Medical Research (AHFMR) Senior Scholar and J.H holds an AHFMR studentship and a Canada Research Scholarship from the Natural Sciences and Engineering Research Council of Canada. This work was supported by an infrastructure grant from the Canadian Foundation for Innovation and from an operating grant from the Canadian Institutes of Health Research.

\section{References}

BELECKY-ADAMS T. and ADLER R. (2001). Developmental expression patterns of bone morphogenetic proteins, receptors and binding proteins in the chick retina. J Comp Neuro/430: 562-572.

BUTLER S.J. and DODD, J. (2003). A role for BMP heterodimers in roof platemediated repulsion of commissural axons. Neuron 38: 389-401.

CHEN D., ZHAO, M. and MUNDY, G.R. (2004). Bone morphogenetic proteins. Growth Factors 22: 233-241.

DUDLEY, A.T., LYONS, K.M. and ROBERTSON, E.J. (1995). A requirement for bone morphogenetic protein-7 during development of the mammalian kidney and eye. Genes Dev 9: 2795-2807.

DUDLEY, A.T. and ROBERTSON, A.T. (1997). Overlapping expression domains of bone morphogenetic protein family members potentially account for limited tissue defects in BMP7 deficient embryos. Dev Dyn 208: 349-362.

FURUTA, Y. and HOGAN, B.L. (1998). BMP4 is essential for lens induction in the mouse embryo. Genes Dev 12: 3764-3775.

HARLAND, R.M. (1991). In situhybridization: an improved whole-mount method for Xenopus embryos. Methods Cel/ Bio/36: 685-695.

HOLT, C.E., BERTSCH, T.W., ELLIS, H.M. and HARRIS, W.A. (1988). Cellular determination in the Xenopus retina is independent of lineage and birth date. Neuron 1: 15-26.

LEE-HOEFLICH, S.T., CAUSING, C.G., PODKOWA, M., ZHAO, X., WRANA, J.L. and ATTISANO, L. (2004). Activation of LIMK1 by binding to the BMP receptor, BMPRII, regulates BMP-dependent dendritogenesis. EMBO J23: 4792-4801.

LIU, J., WILSON, S. and REH, T. (2003). BMP receptor $1 \mathrm{~b}$ is required for axon guidance and cell survival in the developing retina. Dev Bio/256: 34-48.

MEHLER, M.F., MABIE, P.C., ZHANG, D. and KESSLER, J.A. (1997). Bone morphogenetic proteins in the nervous system. Trends Neurosci20: 309-317.

MURALI, D., YOSHIKAWA, S., CORRIGAN, R.R., PLAS, D.J., CRAIR, M.C., OLIVER, G., LYONS, K.M., MISHINA, Y. and FURUTA, Y. (2005). Distinct developmental programs require different levels of $\mathrm{Bmp}$ signaling during mouse retinal development. Development 132: 913-923.

NIEUWKOOP, P.D. and FABER, J. (1994). Normal Table of Xenopus laevis. New York: Garland Publishing Inc.

OSTER, S.F., DEINER, M., BIRGBAUER, E. and SRETAVAN, D.W. (2004) Ganglion cell axon pathfinding in the retina and optic nerve. Semin Cel/ Dev Bio 115: $125-136$.

RIEHL, R., JOHNSON, K., BRADLEY, R., GRUNWALD, G.B., CORNEL, E., LILIENBAUM, A. and HOLT, C.E. (1996). Cadherin function is required for axon outgrowth in retinal ganglion cells in vivo. Neuron 17: 837-848.

SASAGAWA, S., TAKABATAKE, T., TAKABATAKE, Y., MURAMATSU and T., TAKESHIMA, K. (2002). Axes establishment during eye morphogenesis in Xenopus by coordinate and antagonistic actions of BMP4, Shh and RA. Genesis 33: $86-96$

SHI, Y. and MASSAGUE, J. (2003). Mechanisms of TGF-beta signaling from cell membrane to the nucleus. Cel/113: 685-700.

Received: 2nd June 2006

Reviewed by Referees: 13th September 2006 Modified by Authors and Accepted for Publication: 19th October 2006 Published Online: 31st January 2007 